\title{
Palonosetron exhibits higher total control rate compared to first-generation serotonin antagonists and improves appetite in delayed-phase chemotherapy-induced nausea and vomiting
}

\author{
HIROKI UEDA ${ }^{1}$, CHIGUSA SHIMONO ${ }^{1}$, TOMOYASU NISHIMURA ${ }^{2}$, \\ MEGUMI SHIMAMOTO ${ }^{2}$ and HIROKI YAMAUE ${ }^{1,3}$ \\ ${ }^{1}$ Department of Chemotherapy, Oncology Center, ${ }^{2}$ Ambulatory Therapy Center and ${ }^{3}$ Department of Surgery, \\ School of Medicine, Wakayama Medical University, Wakayama, Wakayama, Japan
}

Received September 2, 2013; Accepted January 29, 2014

DOI: $10.3892 / \mathrm{mco} .2014 .263$

\begin{abstract}
In order to ensure the continuity of chemotherapy, it is crucial to provide appropriate supportive care to prevent chemotherapy-induced nausea and vomiting (CINV). The frequency of CINV is greatly affected by the type and combination of chemotherapy employed, which requires further investigation. With the use of patient diaries, a prospective study on the efficacy of antiemetic regimens for nausea and vomiting was conducted in 103 patients receiving highly or moderately emetogenic chemotherapy in the Ambulatory Therapy Center of our institution between August, 2010 and March, 2011. In this study, the efficacy of palonosetron in the delayed phase was affirmed. On days 4 and 5 , in particular, palonosetron exhibited a significantly higher efficacy compared to that of other conventional serotonin $\left(5-\mathrm{HT}_{3}\right)$ receptor antagonists $\left(5-\mathrm{HT}_{3} \mathrm{RAs}\right)$. When the effects of chemotherapy on food intake were assessed by switching granisetron to palonosetron, an improvement in appetite was observed in one-quarter of the cases in the delayed phase. In addition, palonosetron has not been associated with any severe adverse drug reactions. It was therefore suggested that the use of palonosetron be recommended as a $5-\mathrm{HT}_{3} \mathrm{RA}$. In conclusion, our data suggested that palonosetron is effective and may be used as a $5-\mathrm{HT}_{3} \mathrm{RA}$, since it is crucial that we take adequate measures against CINV in order to maintain the patients' quality of life and to develop antiemetic regimens that ensure the continuity of chemotherapy without dose reduction.
\end{abstract}

Correspondence to: Dr Hiroki Ueda, Department of Chemotherapy, Oncology Center, School of Medicine, Wakayama Medical University, 811-1 Kimiidera, Wakayama, Wakayama 641-8510, Japan E-mail: hu11@wakayama-med.ac.jp

Key words: chemotherapy-induced nausea and vomiting, appetite, palonosetron, total control, serotonin receptor antagonists, selective neurokinin-1 receptor antagonist

\section{Introduction}

Chemotherapy-induced nausea and vomiting (CINV) is an adverse event that significantly impairs the patients' quality of life (1). Thus, to ensure the continuity of chemotherapy, it is crucial to provide appropriate supportive care to prevent CINV.

With regard to preventing CINV, antiemetic agents corresponding to each emetogenic risk have been recommended in antiemetic guidelines. Novel antiemetics, such as aprepitant, a selective neurokinin-1 receptor antagonist $\left(\mathrm{NK}_{1} \mathrm{RA}\right)$ and palonosetron, a long-acting second-generation serotonin $\left(5-\mathrm{HT}_{3}\right)$ receptor antagonist $\left(5-\mathrm{HT}_{3} \mathrm{RA}\right)$, were relatively recently developed. Consequently, the guidelines of the American Society of Clinical Oncology (2), the National Comprehensive Cancer Network (3) and the Multinational Association for Supportive Care in Cancer (4) were updated to incorporate aprepitant and palonosetron and their use as antiemetics was recommended, corresponding to either high or moderate emetic risk.

Additionally, in Japan, the antiemetic guidelines issued by the Japan Society of Clinical Oncology (JSCO guidelines) (5) recommend two-drug combinations of a $5-\mathrm{HT}_{3} \mathrm{RA}$ and dexamethasone for use in moderately emetogenic chemotherapy (MEC) and three-drug combinations of a $5-\mathrm{HT}_{3} \mathrm{RA}$, dexamethasone and $\mathrm{NK}_{1} \mathrm{RA}$ for use in highly emetogenic chemotherapy (HEC).

The symptoms of nausea and vomiting are categorized as either acute-phase, defined as episodes occurring within $24 \mathrm{~h}$ of the administration of chemotherapy, or delayed-phase, defined as episodes occurring after $24 \mathrm{~h}(6,7)$. The development of granisetron, a first-generation $5-\mathrm{HT}_{3} \mathrm{RA}$, was shown to mitigate acute nausea and vomiting (8), although its efficacy for delayed nausea and vomiting is limited (9). However, the more recently developed aprepitant (10) and palonosetron (11) have demonstrated promising outcomes in the control of acute- and delayed-phase nausea and vomiting.

In the JSCO guidelines, there is a paragraph highlighting the need to consider the evidence-based proper use of antiemetics upon correctly evaluating the emetogenic risks of each agent. However, the frequency of CINV is greatly dependent 
Table I. Patient characteristics.

\begin{tabular}{|c|c|}
\hline Variables & Patient no. $(n=103)$ \\
\hline Median age, years (range) & $61.6(36-81)$ \\
\hline \multicolumn{2}{|l|}{ Tumor type } \\
\hline Colorectal & 45 \\
\hline Breast & 24 \\
\hline Gynecological & 9 \\
\hline Lung & 8 \\
\hline Biliary & 6 \\
\hline Gastric & 6 \\
\hline Other & 5 \\
\hline \multicolumn{2}{|l|}{ Gender } \\
\hline Male & 41 \\
\hline Female & 62 \\
\hline \multicolumn{2}{|l|}{ Chemotherapy regimen } \\
\hline $\begin{array}{l}\text { HEC (n=42) FEC/CDDP + CPT-11/ } \\
\text { CDDP + GEM/other }\end{array}$ & $21 / 9 / 3 / 9$ \\
\hline $\begin{array}{l}\text { MEC }(n=61) \text { CBDCA }+ \text { PTX/ } \\
\text { Xelox } \pm \text { Bev/FOLFOX } \pm \text { Bev/ } \\
\text { FOLFIRI/IRIS + Bev/other }\end{array}$ & $12 / 22 / 15 / 4 / 1 / 7$ \\
\hline \multicolumn{2}{|l|}{ Prescription of antiemetics } \\
\hline Dexamethasone $+5-\mathrm{HT}_{3} \mathrm{RA}+\mathrm{NK}_{1} \mathrm{RA}$ & 45 \\
\hline Dexamethasone+5- $\mathrm{HT}_{3} \mathrm{RA}$ & 54 \\
\hline $5-\mathrm{HT}_{3} \mathrm{RA}$ alone & 4 \\
\hline \multicolumn{2}{|l|}{ 5-HT ${ }_{3}$ RAs (HEC/MEC) } \\
\hline Granisetron $(n=55)$ & $10 / 45$ \\
\hline Ramosetron $(\mathrm{n}=15)$ & $11 / 4$ \\
\hline Palonosetron $(n=29)$ & $16 / 13$ \\
\hline Azasetron $(n=4)$ & $4 / 0$ \\
\hline \multicolumn{2}{|l|}{$\mathrm{NK}_{1} \mathrm{RA}$ and non-NK ${ }_{1} \mathrm{RA}(\mathrm{HEC} / \mathrm{MEC})$} \\
\hline $\mathrm{NK}_{1} \mathrm{RA}(\mathrm{n}=45)$ & $32 / 13$ \\
\hline Non-NK ${ }_{1}$ RA (n=58) & $10 / 48$ \\
\hline
\end{tabular}

HEC, highly emetogenic chemotherapy; MEC, moderately emetogenic chemotherapy; 5- $\mathrm{HT}_{3}$, serotonin; $5-\mathrm{HT}_{3} \mathrm{RA}, 5-\mathrm{HT}_{3}$ receptor antagonists; $\mathrm{NK}_{1} \mathrm{RA}$, selective neurokinin-1 receptor antagonist. FEC, fluorouracil + epirubicin + cyclophosphamide; CDDP, cisplatin; IRIS, irinotecan + S-1; CPT-11, irinotecan; GEM, gemcitabine; XELOX, capecitabine + oxaliplatin; Bev, bevacizumab; FOLFOX, folinic acid + fluorouracil + oxiplatin; FOLFIRI, folinic acid + fluorouracil + irinotecan; CBDCA, carboplatin; PTX, paclitaxel.

on the type and combination of chemotherapeutic agents, which requires further investigation.

Thus, in an attempt to assess the efficacy of the currently available antiemetic agents for nausea and vomiting following standard chemotherapy,we conducted a prospective study through the use of patient diaries on nausea and vomiting.

\section{Materials and methods}

Population. In the present study, participants were recruited among patients receiving HEC or MEC in the Ambulatory Therapy Center of our institution between August, 2010 and
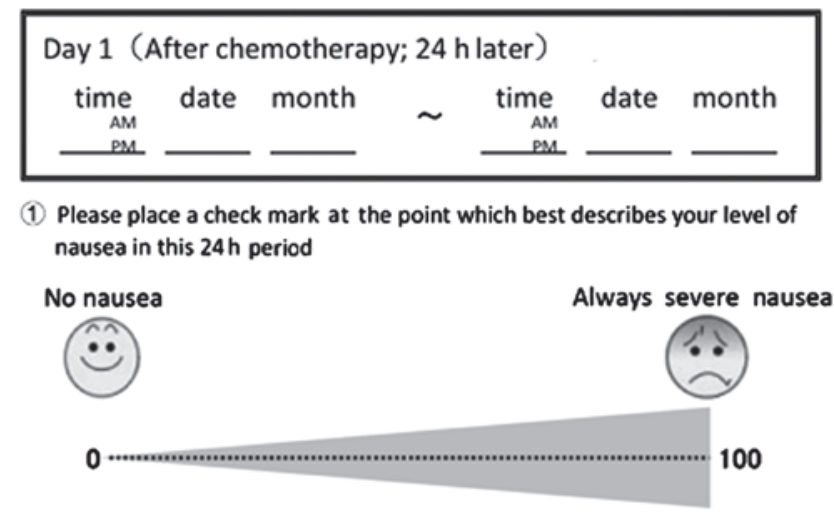

(2) Has there been any vomiting in the last $\mathbf{2 4}$ hours?
$\square$ No

(3) Have you been able to eat as usual ?

$\square$ As usual

$\square$ Nausea, appetite was lost

$\square$ Nausea, amount to eat reduced

$\square$ Nausea, cannot eat most of the food

(4) Please answer, if you have received the same chemotherapy as before. Did the degree of nausea change in comparison with the past?

$\square$ Better $\quad \square$ Nochange $\quad \square$ Worse

(5) Did you add the antiemetics because of severe nausea?

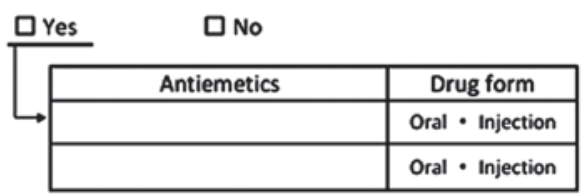

Figure 1. Example of patients' diaries used to assess the episodes of nausea and vomiting from the day of treatment until day 5.

March, 2011. Patients with episodes of vomiting within $24 \mathrm{~h}$ prior to the administration of chemotherapy, those who required the administration of HEC or MEC on or after day 2 and those who received radiation therapy were excluded from the study.

The study protocol was approved by the Institutional Review Board prior to the initiation of the study and all the patients provided written informed consent prior to enrollment.

Assessment of antiemetic efficacy and safety. The episodes of nausea and vomiting were assessed through the use of patient diaries from the day of the treatment until day 5 (Fig. 1). The efficacy endpoints were defined as follows: Complete response (CR), no emetic episodes and no rescue therapy; and total control (TC), no emetic episodes, no rescue therapy, no nausea and no appetite loss. The patients' diaries, in which the scores on the visual analogue scale (VAS) for assessing the severity of nausea $(12,13)$, the presence of vomiting episodes and the appetite levels were recorded by the patients themselves over a period of 5 days, were collected and assessed. The appetite levels were recorded with a four-grade assessment system: Normal, appetite diminished due to nausea, food portions decreased due to nausea and almost no food intake due to nausea.

Statistical analysis. In order to compare the assessments of antinausea or antiemetic activity, a statistical analysis was 

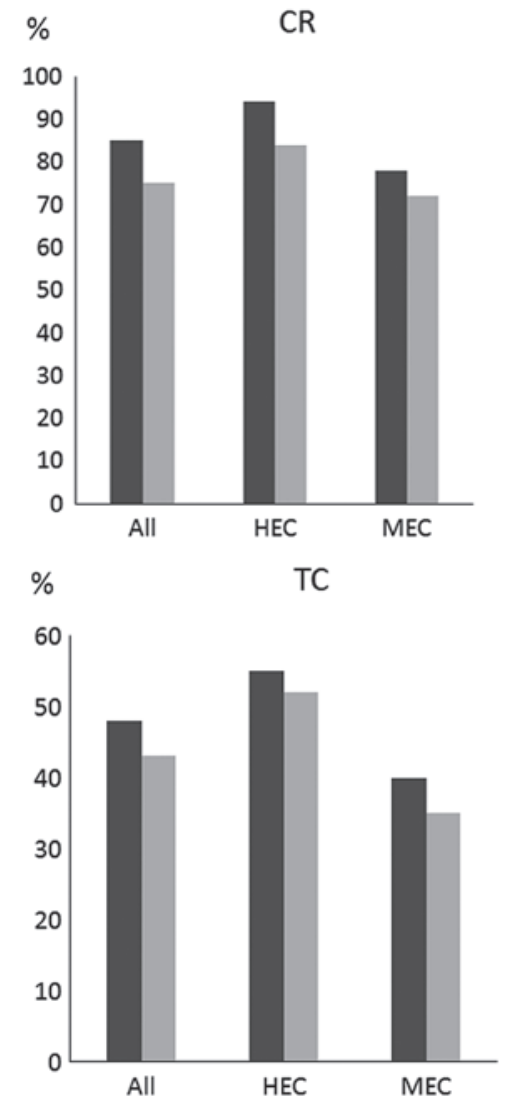

Figure 2. Complete response (CR; no emetic episodes and no rescue therapy) and total control (TC; no emetic episodes, no rescue therapy, no nausea and no appetite loss) rates in the delayed phase by emetogenic drugs (HEC, patients receiving highly emetogenic chemotherapy; MEC, patients receiving moderately emetogenic chemotherapy).

performed using the $\chi^{2}$ test. The level of significance was set at 0.05 for all the tests. All the statistical analyses were performed using JMP software, version 9.0.2 (SAS Institute, Cary, NC, USA).

\section{Results}

Patient characteristics. The characteristics of the 103 patients are shown in Table I. The patients included 41 men and 62 women, with a median age of 61.6 years (range, 36-81 years). A total of 42 patients received HEC and 61 patients received MEC. The tumor types included colorectal (45), breast (24), gynecological (9), lung (8), biliary tract (6), gastric (6) and other types of cancer (5). The chemotherapeutic regimens used were as follows: for HEC, fluorouracil + epirubicin + cyclophosphamide; cisplatin $(\mathrm{CDDP})+$ gemcitabine; or CDDP + irinotecan (CPT-11); and for MEC, capecitabine + oxaliplatin/folinic acid + fluorouracil + oxiplatin \pm bevacizumab (Bev); folinic acid + fluorouracil + irinotecan (FOLFIRI)/irinotecan + S-1 (IRIS) $\pm \mathrm{Bev}$; or CBDCA + paclitaxel. The four agents used as a $5-\mathrm{HT}_{3} \mathrm{RA}$ were granisetron hydrochloride (granisetron), azasetron hydrochloride (azasetron), ramosetron hydrochloride (ramosetron) and palonosetron hydrochloride (palonosetron). One of these $5-\mathrm{HT}_{3} \mathrm{RAs}$ plus dexamethasone and aprepitant (a three-drug combination) was administered to 42 patients.

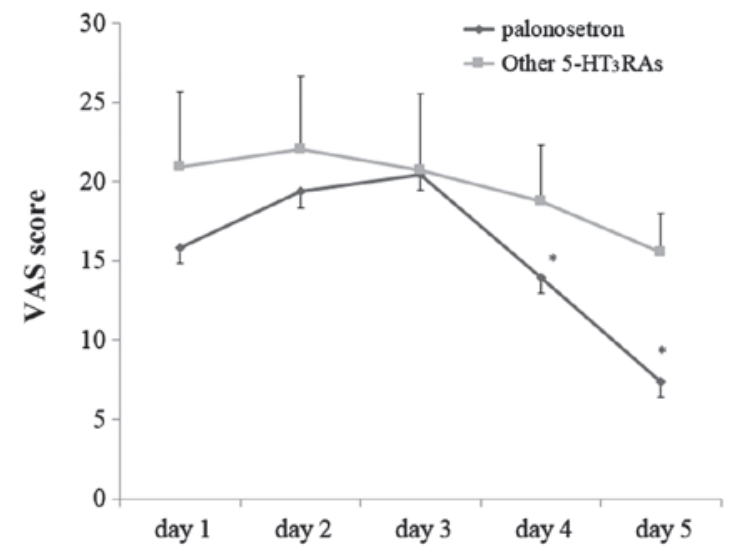

Figure 3. Visual analogue scale (VAS) score in patients receiving palonosetron or other serotonin $\left(5-\mathrm{HT}_{3}\right)$ receptor antagonists $\left(5-\mathrm{HT}_{3} \mathrm{RAs}\right)$. The error bars indicate the standard error. ${ }^{*} \mathrm{P}<0.05$ compared to the reduction rate with other $5-\mathrm{HT}_{3} \mathrm{RAs}$.

Efficacy. The CR and TC rates in the delayed phase were assessed for all the patients and for those receiving HEC and MEC, by comparing the patients administered palonosetron (group P) to those administered a different 5-HT ${ }_{3}$ RA (group X) (Fig. 2). The CR rates for all, HEC and MEC patients in group $\mathrm{P}$ vs. those in group $\mathrm{X}$ were 86 vs. $76 \%, 93$ vs. $84 \%$ and 77 vs. $72 \%$, respectively. The TC rates for all, HEC and MEC patients in group $\mathrm{P}$ vs. those in group X were 48 vs. $43 \%, 55$ vs. $52 \%$ and 40 vs. $35 \%$, respectively. Although both groups exhibited an improvement in the VAS scores in the delayed phase over time (Fig. 3), the changes exhibited by group $\mathrm{P}$ patients were more prominent compared to those exhibited by group $\mathrm{X}$ patients.

The changes in the VAS scores in the delayed phase (days 2-5) in HEC and MEC patients were further assessed. In HEC patients, the VAS scores on day 5 were lower in group $\mathrm{P}$ patients compared to those in group X patients (Fig. 4A). When the reduction in the VAS scores on days 3-5 in HEC was assessed by defining the scores of day 2 as $100 \%$, the decrease in VAS scores on day 5 in group $\mathrm{P}$ patients was significantly more prominent, with a more significant improvement compared to that in group X patients (Fig. 4B). Furthermore, as regards MEC patients, the VAS scores in group $\mathrm{P}$ were also lower compared to those in group X on days 4 and 5 (Fig. 4C); when the relative reduction in VAS scores in group $\mathrm{P}$ patients after day 2 was assessed, the decrease in VAS scores on days 4 and 5 in group P patients was significantly more prominent compared to that in group $\mathrm{X}$ patients (Fig. 4D).

Furthermore, changes in food intake were assessed in 18 patients in whom granisetron was switched to palonesetron (Fig. 5). In the delayed phase, a total of $22.2 \%$ (4/18) of the patients attained increased food intake and exhibited improved appetite.

\section{Discussion}

5-HT ${ }_{3}$ RAs, $\mathrm{NK}_{1}$ RAs and dexamethasone are effective antiemetic agents used to prevent CINV. In Japan, $\mathrm{NK}_{1} \mathrm{RAs}$ are currently covered by public health insurance and palonosetron has become available as a second-generation $5-\mathrm{HT}_{3} \mathrm{RA}$. These 
A

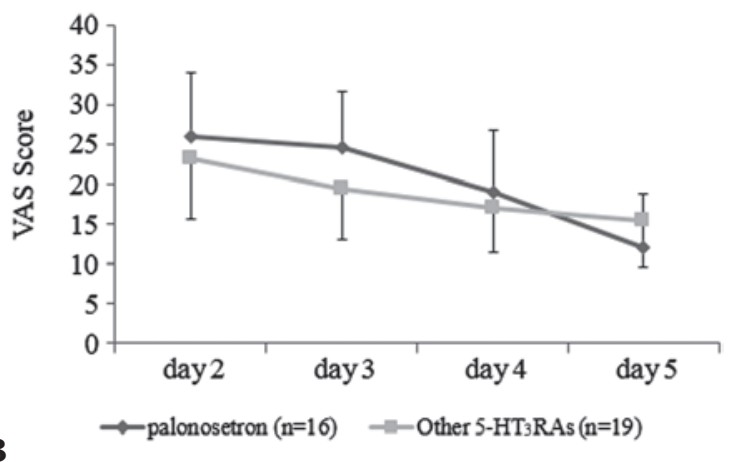

B

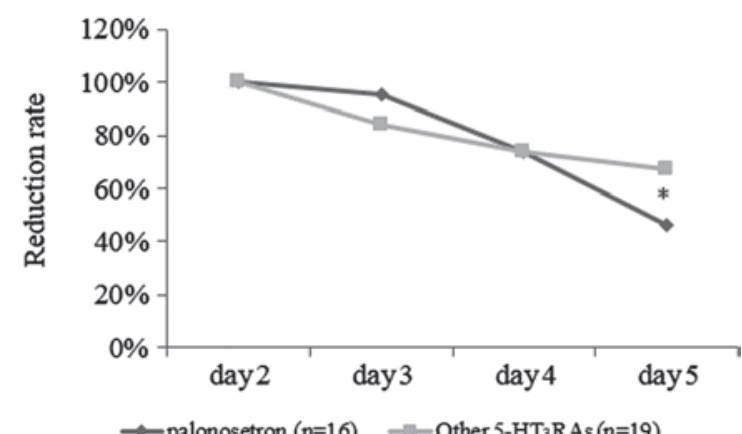

$\mathbf{C}$

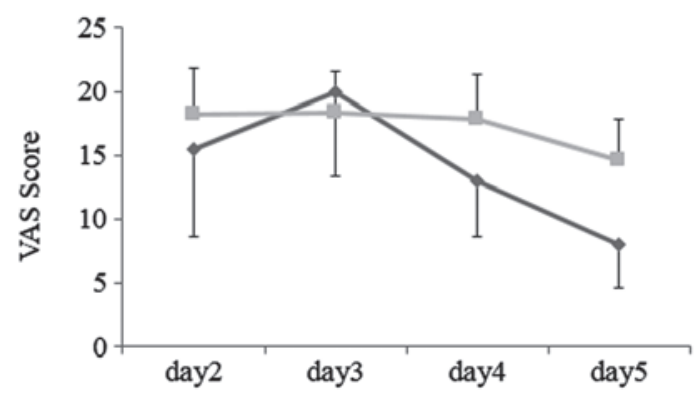

D

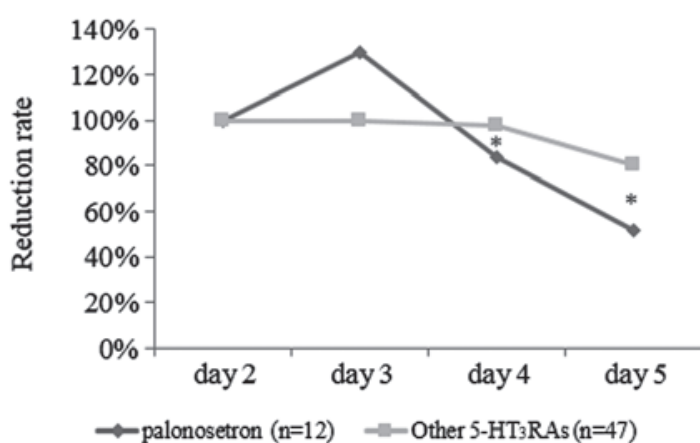

Figure 4 Visual analogue scale (VAS) score and reduction rate of VAS score in the delayed phase. (A and B) Patients receiving highly emetogenic chemotherapy (HEC); (C and D) patients receiving moderately emetogenic chemotherapy (MEC). The error bars indicate the standard error. ${ }^{*} \mathrm{P}<0.05$ compared to the reduction rate with other $5-\mathrm{HT}_{3} \mathrm{RAs}$. $5-\mathrm{HT}_{3}$, serotonin; $5-\mathrm{HT}_{3} \mathrm{RAs}, 5-\mathrm{HT}_{3}$ receptor antagonists.

antiemetics are also recommended in guidelines published in the USA and Europe (2-4).

The efficacy of palonosetron was demonstrated in the present study. Palonosetron exhibited a greater efficacy
A

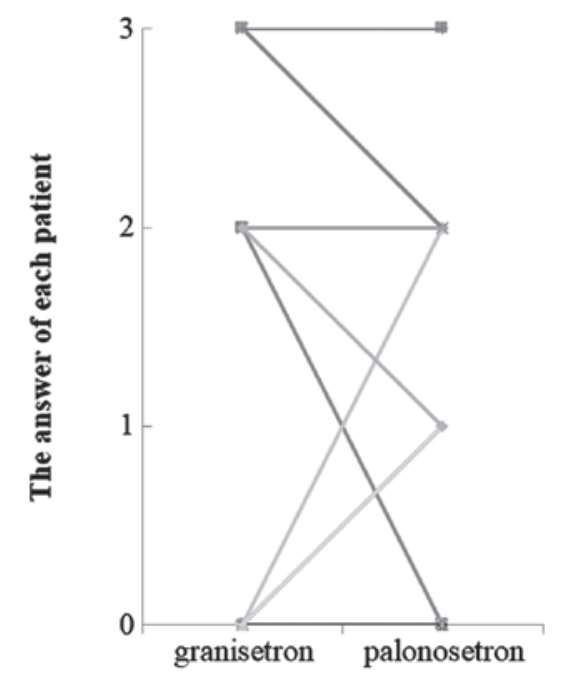

B

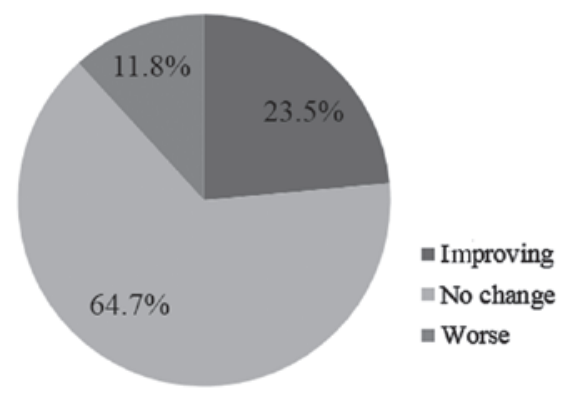

Figure 5. Effect on appetite in the delayed phase in 18 patients who were switched from granisetron to palonosetron. (A) Changes in food intake $(0$, usual appetite; 1 , no appetite due to nausea; 2 , food consumption reduced due to nausea; 3 , patients unable to eat most of the food due to nausea); (B) ratio of changes.

compared to other conventional 5- $\mathrm{HT}_{3} \mathrm{RAs}$, particularly on days 4 and 5 , as it has a long half-life (14); it was also found to be effective in HEC and MEC in the delayed phase. In certain cases in the present study, granisetron was replaced by palonosetron in an attempt to achieve higher efficacy of the newly developed antiemetics to determine the effects of chemotherapy on food intake. Improvements in appetite were previously reported (11), particularly in the delayed phase, in one-quarter of the patients in whom the antiemetic agent was switched to palonosetron. There were no serious side effects and, although there has not yet been a listing of palonosteron in the Japanese guidelines (5), it was suggested that the use of palonosetron as a $5-\mathrm{HT}_{3} \mathrm{RA}$ be prioritised over that of other available $5-\mathrm{HT}_{3} \mathrm{RAs}$.

Additionally, improvement of the VAS scores on days 4 and 5 is crucial in terms of maintaining the nutritional status and reducing the time of appetite loss. However, there were certain limitations to our study. When CR and TC rates in the delayed phase were assessed by HEC and MEC regimens, the TC rates for both groups were low; in particular, the TC rates in MEC were 33\%, which is lower compared to the $51.9 \%$ previously reported (15). This discrepancy may be attributed to the TC rate in the present study being more strictly defined 
[i.e., complete control (CC) was previously defined as "no nausea and no vomiting']. The other plausible cause for these discrepancies may be the fact that there were some cases in which dexamethasone was not administered on days 2 or 3 . In fact, in those cases receiving the guideline-directed regimens, the $\mathrm{CC}$ rates were almost equivalent to those previously reported (data not shown). The detailed mechanism through which dexamethasone mitigates nausea and vomiting has not been fully elucidated (16); however, it is an evidence-based agent reported to exhibit high dose-dependent efficacy (17). The present study demonstrated that the $\mathrm{CR}$ and $\mathrm{TC}$ rates were decreased in the corresponding dexamethasone-free regimens, indicating that guideline-directed antiemetic therapies should be recommended. However, the development of dexamethasone-free regimens is required for patients who are unable to tolerate the adverse effects of dexamethasone, including hyperglycemia and insomnia $(18,19)$.

The JSCO guidelines recommend the use of two-drug combinations for antiemetic regimens against CINV in MEC (20); however, by definition, the frequency of CINV episodes in MEC is 30-90\% (21) and the addition of aprepitant to certain antineoplastic agents has been recommended. CPT-11-based regimens, including FOLFIRI and IRIS, one of the major chemotherapeutic regimens for colorectal cancer, are another example. Our results demonstrated that the CR and TC rates in CPT-11-based regimens were lower and the VAS scores were significantly higher compared to the other MEC regimens (data not shown). Thus, we concluded that it may be necessary to include $\mathrm{NK}_{1} \mathrm{RA}$ as part of the three-drug combination (5-HT ${ }_{3} \mathrm{RA}, \mathrm{NK}_{1} \mathrm{RA}$ and dexamethasone), similar to HEC. Additionally, there have been a number of cases in which breakthrough emesis developed despite the patient being on a three-drug antiemetic regimen, which is another major issue of CINV that needs to be addressed in the immediate future. Although existing guidelines recommend the use of domperidone and metoclopramide as adjunct agents (5), the efficacy of these agents was not found to be satisfactory. Olanzapine has relatively recently gained recognition for its efficacy against hard-to-control CINV (22), becoming one of the promising antiemetics. Furthermore, the use of Rikkunshito a traditional Japanese (Kampo) medicine, previously shown to be efficient against appetite loss in CDDP regimens (23), also needs to be taken into consideration.

In conclusion, our data indicated that palonosetron is effective and may be recommended as a $5-\mathrm{HT}_{3} \mathrm{RA}$, as it is crucial that we take adequate measures against CINV to maintain the patients' quality of life and develop antiemetic regimens that ensure the continuity of chemotherapy without dose reduction.

\section{References}

1. Neymark $\mathrm{N}$ and Crott $\mathrm{R}$ : Impact of emesis on clinical and economic outcomes of cancer therapy with highly emetogenic chemotherapy regimens: a retrospective analysis of three clinical trials. Support Care Cancer 13: 812-818, 2005.

2. American Society of Clinical Oncology, Kris Mg, Hesketh PJ, Somerfield MR, et al: American Society of Clinical Oncology guideline for antiemetics in oncology: update 2006. J Clin Oncol 24: 2932-2947, 2006.
3. National Comprehensive Cancer Network. NCCN Practice Guidelines in Oncology. Available at: www.nccn.org. Accessed, August 10, 2013.

4. Rolia F, Herrstedt J, Aapro M, et al; ESMO/MASCC Guidelines Working Group: Guideline update for MASCC and ESMO in the prevention of chemotherapy- and radiotherapy-induced nausea and vomiting: results of the Perugia consensus conference. Ann Oncol 21: v232-v243, 2010.

5. Japan Society of Clinical Oncology: Guidelines for antiemetics in Oncology 2010, 1st edition, Japan: Kanehara Publishing Company Ltd.; Tokyo, Japan.

6. Tavorath $\mathrm{R}$ and Hesketh PJ: Drug treatment of chemotherapy-induced delayed emesis. Drugs 52: 639-648, 1996.

7. Hesket PJ: Chemotherapy-induced nausea and vomiting. N Engl J Med 358: 2482-2494, 2008

8. del Giglio A, Soares HP, Capparoz C and Castro PC: Granisetron is equivalent to ondansetron for prophylaxis of chemotherapy-induced nausea and vomiting: results of a meta-analysis of randomized controlled trials. Cancer 89: 2301-2308, 2000

9. Geling $\mathrm{O}$ and Eichler HG: Should 5-hydroxytryptamine-3 receptor antagonists be administered beyond 24 hours after chemotherapy to prevent delayed emesis? Systematic re-evaluation of clinical evidence and drug cost implications. J Clin Oncol 23: 1289-1294, 2005.

10. Warr DG, Hesketh PJ, Gralla RJ, et al: Efficacy and tolerability of aprepitant for the prevention of chemotherapy-induced nausea and vomiting in patients with breast cancer after moderately emetogenic chemotherapy. J Clin Oncol 23: 2822-2830, 2005.

11. Saito M, Aogi K, Sekine K, et al: Palonosetron plus dexamethasone versus granisetron plus dexamethasone for prevention of nausea and vomiting during chemotherapy: a double-blind, double-dummy, randomised, comparative phase III trial. Lancet Oncol 10: 115-124, 2009.

12. Börjeson S, Hursti TJ, Peterson C, et al: Similarities and differences in assessing nausea on a verbal category scale and a visual analogue scale. Cancer Nurs 20: 260-266, 1997.

13. Del Favero A, Roila F, Basurto C, et al: Assessment of nausea. Eur J Clin Pharmacol 38: 115-120, 1990.

14. Maemondo M, Masuda N, Sekine I, et al: A phase II study of palonosetron combined with dexamethasone to prevent nausea and vomiting induced by highly emetogenic chemotherapy. Ann Oncol 20: 1860-1866, 2009.

15. Eisenberg P, Figueroa-Vadillo J, Zamora R, et al; 99-04 Palonosetron Study Group: Improved prevention of moderately emetogenic chemotherapy-induced nausea and vomiting with palonosetron, a pharmacologically novel $5-\mathrm{HT}_{3}$ receptor antagonist. Cancer 98: 2473-2482, 2003.

16. Ho CM, Wu HL, Ho ST and Wang JJ: Dexamethasone prevents postoperative nausea and vomiting: benefit versus risk. Acta Anaesthesiol Taiwan 49: 100-104, 2011.

17. No authors listed: Double-blind, dose-finding study of four intravenous doses of dexamethasone in the prevention of cisplatin-induced acute emesis. Italian Group for Antiemetic Research. J Clin Oncol 16: 2937-2942, 1998.

18. Grunberg SM: Antiemetic activity of corticosteroids in patients receiving cancer chemotherapy: dosing, efficacy, and tolerability analysis. Ann Oncol 18: 233-240, 2007.

19. Tonato M, Clark-Snow RA, Osoba D, et al: Emesis induced by low or minimal emetic risk chemotherapy. Support Care Cancer 13: 109-111, 2005.

20. Italian Group for Antiemetic Research: Dexamethasone, granisetron, or both for the prevention of nausea and vomiting during chemotherapy for cancer. N Engl J Med 332: 1-5, 1995.

21. Roila F, Hesketh PJ, Herrstedt J, et al: Prevention of chemotherapy- and radiotherapy-induced emesis: results of the 2004 Perugia international antiemetic consensus conference. Ann Oncol 17: 20-28, 2006.

22. Tan L, Liu J, Liu X, et al: Clinical research of olanzapine for prevention of chemotherapy-induced nausea and vomiting. J Exp Clin Cancer Res 23: 131, 2009.

23. Takeda H, Sadakane C, Hattori T, et al: Rikkunshito, an herbal medicine, suppresses cisplatin-induced anorexia in rats via 5- $\mathrm{HT}_{2}$ receptor antagonism. Gastroenterology 134: 2004-2013, 2008. 